\title{
O USO DE NOVAS TECNOLOGIAS E AS COMUNIDADES DE PRÁTICA NA EDUCAÇÃO: UMA CONTRIBUIÇÃO À PRAXIS DOCENTE
}

\author{
IVATUBA/PR JUNHO/2018
}

\author{
Reginéa de Souza Machado－UNICESUMAR - regineapsico@gmail.com \\ Marcio Fraiberg Machado - IAP-Faculdade - profmarciofraiberg@gmail.com \\ Evandro Lombardi - IAP-Faculdade - lombardicpb@gmail.com \\ Geórgia de Souza Machado－ UNASP-EC - georgiasmachado@gmail.com
}

Tipo: Relato de Experiência Inovadora (EI)

Categoria: Métodos e Tecnologias

Setor Educacional: EDUCAÇÃO MÉDIA E TECNOLÓGICA

\begin{abstract}
RESUMO
Este trabalho pretende fornecer uma contribuição à sala de aula e a práxis do professor de Biologia do ensino médio. Utiliza-se das novas tecnologias aliadas as técnicas de Gestão do Conhecimento e de ensino à distância (EAD), para o estudo/ ensino de Ecologia no próprio ambiente de atuação dos docentes. Pretende-se uma contribuição à práxis do professor sugestionando o uso de um aplicativo em geoprocessamento para análise e discussão da temática. Procurou-se intervir com uma proposta de tema em sala de aula, e posterior entrevista aos professores e alunos de uma turma de 30 ano de escola pública. Objetivou-se oferecer uma contribuição, do uso de novas tecnologias aliadas ao ensino à distância, que auxiliassem, de maneira intuitiva, reunir gratuidade e dados suficientes a uma (re)leitura do ambiente, permitindo que o aluno pudesse gerir essas informações, Para que isso ocorra, procuramos oferecer como opção pedagógica o Software Google Earth Engine, com possíveis encaminhamentos para uso em sala de aula.
\end{abstract}

Palavras-chave: Novas tecnologias. Ensino à Distância, Ecologia, Gestão do Conhecimento. Geoprocessamento. 


\section{INTRODUÇÃO}

Esse trabalho é continuidade de um projeto mais amplo que envolve o uso de novas tecnologias e a formação de comunidades de prática na educação, pois quando se discute os processos de ensino e aprendizagem, o uso de tecnologias em sala de aula, tem avançado a passos largos em sua oferta. Mas e sua procura? Tem obtido o mesmo êxito? De modo geral pode-se perceber um grande interesse por parte dos alunos o aprender com o uso de novas tecnologias digitais de Informação e Comunicação (TDIC), mas, em contrapartida, o quadro não parece animador no que diz respeito a resposta docente, pois somente $2 \%$ usa tecnologia em sala de aula (TPE, 2013).

Isso se deve, cremos, a possível dificuldade dos docentes acerca das grandes possibilidades de aprendizado favorecido pelos ambientes virtuais e o fato deles próprios não terem acompanhado as grandes mudanças sociais produzidas pelo uso de NT e o ensino à distância (EaD). Faz-se necessário uma mudança de paradigma no ensino tradicional e presencial para um maior aproveitamento da dimensão virtual (RODRIGUES, MOURA, TESTA, 2015; PRENSKY, 2001).

A forma como as aulas tradicionais são ministradas não contemplam inúmeros itens encontrados nos ambientes virtuais, especialmente na modalidade $\mathrm{EaD}$, desde 0 interesse dos alunos pelas tecnologias; a flexibilidade de uso independente do horário de acesso e localização geográfica; bem como, a possibilidade de se pesquisar e aprender em grupo, dentre outros aspectos que podem ser destacados na literatura.

Algumas pesquisas têm demonstrado que as práticas educacionais atuais não contemplam itens que são encontrados nos ambientes virtuais e que poderiam em muito contribuir para o ambiente de sala de aula (TAKAHASHI, 2000; LIBÂNEO, 2001; BESCKOW, 2015). Assim, intentamos despertar o interesse para a utilização e coleta de informações usando TDIC gratuitas e disponíveis em dispositivos móveis, de fácil acesso e nos momentos geridos pelos usuários em EaD, para a ressignificação do papel cidadão que o aluno possui, de forma a participar do processo, incluir-se como produtor desse conhecimento e gerí-lo na produção de algo pertinente e útil a sua tomada de decisão.

O uso das TDIC como ferramenta na gestão do conhecimento, ampliam o processo de ensino e aprendizagem, permitindo uma interconexão entre professores, estudantes e comunidade, ampliando e criando espaços e cenários que miscigenam inúmeras linguagens (TONINI, 2013). Por estarem familiarizados com as TDIC, os estudantes necessitam apenas de um direcionamento para o uso das mesmas para fins educacionais. A utilização da plataforma Google Earth Engine (GEE) e do AVA propiciam a construção de uma nova postura na exploração do espaço ecológico, especialmente o da ocupação humana que, em muitos casos, é desordenado e altamente destrutivo à flora e a fauna de uma região. 


\section{OBJETIVOS:}

Para a construção dos elementos da intervenção, analisamos os dados relativos a práxis de sala de aula, a recepção do conteúdo pelos estudantes, a ecologia do ambiente, seu mapeamento e escolha das imagens que ao longo do tempo mostram os processos ecológicos em ação. Em cada grupo se desejou compreender os objetivos: a. Um olhar estrutural sobre a natureza com o uso de TDIC; b. A percepção da biocenose e reconhecimento do biótopo usando o GEE em EaD; c. A percepção das sucessões ecológicas via GEE; d. A análise da biogeografia do ambiente; e. A análise da ação humana no ambiente.

\section{REFERENCIAL TEÓRICO}

Em nossa sociedade é crescente a procura por novas e eficazes formas, estruturas, metodologias e práticas para um eficiente aprender e ensinar, especialmente usando as TDIC. Para assim ampliar sua dispersão e proporcionando o afastamento de barreiras físicas (BIZZOTO, 2000). Essas TDIC permitem construir uma nova relação com o conhecimento, pois amplia os recursos a disposição e permite coletar/analisar uma maior quantidade de informações. Cabe ao educador proporcionar esse contato e depuramento da informação, não utilizando a tecnologia apenas para receber informações, mas para ler/interpretar, pensar, discutir e criar alternativas com o objeto analisado (CHAVES, 2004). O ensino das geociências tem sido restringido a teoria em sala de aula, olvidando a prática e ela "é fundamento, finalidade e critério de verdade da teoria. A primazia da prática sobre a teoria, longe de implicar contradição ou dualidade, pressupõe íntima vinculação a ela" (VÁZQUEZ, 1997, apud GIMENES, 2011. p. 35 36). Nossa contribuição ocorre no sentido de auxiliar o aluno numa ponte entre as TDIC e o processo educativo, com objetivos práticos para um ensino e aprendizagem significativo e de qualidade.

\footnotetext{
o Google Earth Engine integra-se ao desenvolvimento curricular nas Escolas, tornando-se uma ferramenta que possibilita aos professores a mediação do processo de ensino-aprendizagem, e ajuda aos alunos a adquirir uma postura de aprendizes pensadores/investigadores, diante dos conteúdos apresentados. Não substituindo as aulas, mas acrescentando outro recurso didático, inovador e interessante para manter a atenção do aluno, despertando sua curiosidade e vontade de aprender. (CANÃ et al, 2015, p.554).
}

Há que se mencionar outro fator importante como, o uso da ferramenta em situações fora do contexto regional do aluno. As sugestões de trabalhos escolares usando a ferramenta, em sua maioria, são relativos a espaços que não são o do aluno, desprezando, por exemplo, sua localidade ou seu estado de origem. Ao explorar a temática mais atual, da ocupação e expansão humana, em relação ao meio ambiente, o aluno inicia sua jornada a uma cidadania plena, de participação objetiva nas decisões políticas de sua cidade/bairro. 


\section{PROCEDIMENTOS METODOLÓGICOS}

$\mathrm{Na}$ estruturação desse trabalho, trabalhamos com etapas de construção. Primeira Etapa: procedemos a coleta de dados de como a temática está sendo trabalhada e assimilada em dois grupos de pesquisa, o de professores e o de alunos (Tabela 1), em escola privada, da região de Ivatuba, Noroeste do Paraná, cidade onde os autores trabalham. A instituição educacional visitada conta com duas turmas de ensino médio, com 2 professores na área de Biologia e 1 professor interessado (Geografia) no processo e 46 alunos participaram do projeto.

A temática analisada é o ensino de Ecologia, nas aulas de Biologia. Essas entrevistas ocorreram no segundo semestre de 2017 e foram informais, não objetivaram um registro acurado, pois a intenção era colher um feedback, algo livre de estruturação e com isso, um possível "mascaramento", de como a temática é explorada e recebida, algo que um instrumento oficial poderia não permitir.

Segunda Etapa: Ofereceu-se aos professores um projeto de intervenção, onde os pesquisadores auxiliariam na construção de uma aula de ecologia, utilizando novas tecnologias em regime presencial e à distância. Essa problemática, nos levou a estudar um meio de relacionar e dar significado a uma área fundamental para a efetiva cidadania, que é a forma como utilizamos o meio ambiente com as TDIC.

[...] a análise de um sistema computacional com finalidades educacionais não pode ser feita sem considerar o seu contexto pedagógico de uso. Um software só pode ser tido como bom ou ruim dependendo do contexto e do modo como ele será utilizado. Portanto, para ser capaz de qualificar um software é necessário ter muito clara a abordagem educacional a partir da qual ele será utilizado e qual o papel do computador nesse contexto. E isso implica ser capaz de refletir sobre a aprendizagem a partir de dois pólos: a promoção do ensino ou a construção do conhecimento pelo aluno (VALENTE, 1997, p. 19).

Para a construção da intervenção, com base nas conversas com professores e alunos, percebemos, dois pontos fundamentais na busca por um software adequado ao ensino de ecologia à situação apresentada, de estudantes inseridos num contexto agrícola: a. o desconhecimento das ferramentas de geotecnologia e; b. a carência na divulgação e estudo do uso de TDIC na área de ecologia, para a sala de aula. Um dado interessante que constatamos, foi o de que $100 \%$ de professores e alunos possuem acesso a internet.

Após as etapas de análise, passamos a proposta de intervenção. Assim, foi elaborado um conjunto de 5 aulas ( 1 por semana), das 3 a que professor teria com a turma, sobre a temática "ocupação do espaço ecológico", na área de Ecologia, na disciplina de Biologia, do 30 ano do ensino médio, turma que contempla jovens de 16 a 19 anos de uma escola privada, da cidade de Ivatuba, no Estado do Paraná. O período adotado para o estudo foi o de meados de agosto e setembro de 2017. Para a construção da temática, cada aula presencial era seguida de momentos de busca e pesquisa no 
formato EaD. Seguem-se as etapas de trabalho:

Etapa 1: Em sala de aula, adotamos uma postura de diálogo sobre a compreensão que os alunos apresentavam a respeito da ecologia no município e a forma como esses viam em seu dia-a-dia. Usamos Power Point com imagens da Terra, do continente e do Estado e recortes de jornal sobre a temática ambiental. Esse momento, nos permitiu realizar ajustes na metodologia do conteúdo, adequando-o as necessidades dos alunos, bem como a sua capacidade cognitiva em relação à temática. Nessa etapa, intervimos no sentido de ampliar os conhecimentos a respeito do sensoriamento remoto, do espaço geográfico, da ação dos satélites, e do retorno que esses proporcionariam.

Questões sobre, se reconheciam a utilização de produtos de sensoriamento remoto em seus dispositivos móveis? A forma como os usamos? Foram sendo construídas pelos alunos, e explicitadas pelo grupo de pesquisa. Houve um imediato reconhecimento das imagens pelos alunos, do que veem em telejornais e jornais, especialmente a "previsão do tempo", pois "a mídia está presente em todos os momentos de nossos dias e, de certa forma, onipresente na produção da informação, como fonte" (TONINI, 2011, p.94). Etapa 2: Após a interação com o sensoriamento remoto, apresentamos as geotecnologias e sua utilização na coleta de dados para o estudo da ecologia. Buscamos por um software que possa ser utilizado na área de Ciências Naturais e da Terra, especialmente em ecologia, e elaboramos os requisitos essenciais a sua escolha: a. Gratuidade; b. Fácil utilização e/ou propriedades intuitivas de utilização; c. Carregamento rápido e simplificado; d. Amplo espectro de utilização; e. fidelidade das informações prestadas.

Após a análise dos vários softwares disponíveis com os critérios elaborados, optou-se pelo Google Earth Engine (GEE). Aplicar o software gratuito GEE (figura 1), as necessidades da sala de aula e a multidisciplinaridade necessária a essa proposta, foi tarefa esperada pelos alunos. A plataforma google, já é conhecida de todos eles, daí sua facilidade de operação. Esse software consiste num sistema que organiza milhares de imagens, antigas e atuais, a fim de comparar e monitorar o meio ambiente ao longo do tempo.

A plataforma foi construída para vários pesquisadores da area de geociências e facilita o trabalho de mapeamento e interpretação de dados, sendo útil para verificar mudanças climáticas, níveis de desmatamento, mapeamento de águas e, até mesmo, as consequências de diversos desastres naturais. No youtube, existem tutoriais (em língua inglesa), que orientam novas formas de utilizá-lo em sala de aula (GOOGLE, 2016).

Num primeiro momento, apresentamos a plataforma na sala de informática, que dispõe de 20 computadores. Começamos a questionar a respeito do que tem acontecido com nosso município e que alterações tem ocorrido ao longo do tempo. Com base no software, foi possível analisar e acompanhar sua evolução. O Google Earth mapeia o 
planeta, utilizando fotos de satélite e posição de geoprocessamento (GPS). O GEE as acumula ao longo do tempo, permitindo visualizá-las e perceber as alterações no terreno (figuras 1 e 2).

Figuras 1 e 2: Imagens de Ivatuba ao longo do tempo

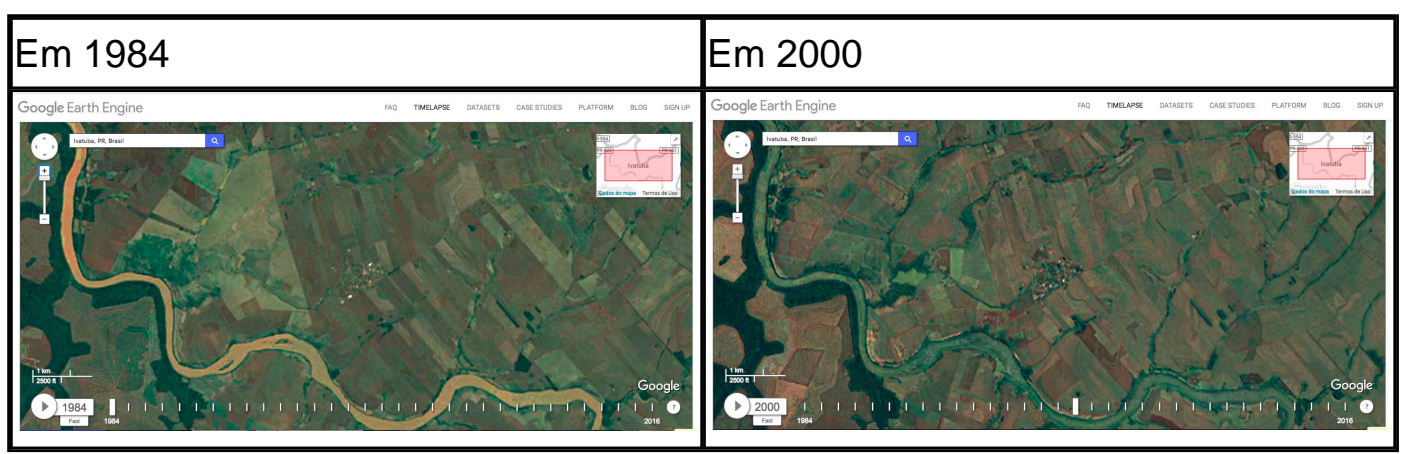

Fonte: Arquivos do Google Earth Engine

Após a demonstração e a primeira coleta de dados, montamos os grupos de pesquisa em EaD, responsáveis por coletas mais objetivas dos dados necessários a exploração da temática Ecologia, algo que supera o tempo em sala de aula. Todos os participantes possuem dispositivos móveis conectados a internet, o que possibilitou a execução dessa etapa: a. Grupo de análise do espaço geográfico: Com o uso do GEE, os alunos destacaram a evolução de nossa cidade, percebendo a formação de um novo bairro e a expansão de outros. b. Grupo de análise da situação agrária: Perceberam as mudanças no terreno, pois na cidade é tradicional a rotação de grandes culturas (milho - soja), mostrando épocas de grandes chuvas e grande seca. c. Grupo de análise do assoreamento: Perceberam o lento e gradual assoreamento do rio que corta a cidade e o desaparecimento de "olhos d'água", tão comuns no meio da plantação (figura 3).

Figura 3: A cidade analisada em imagem de 2016

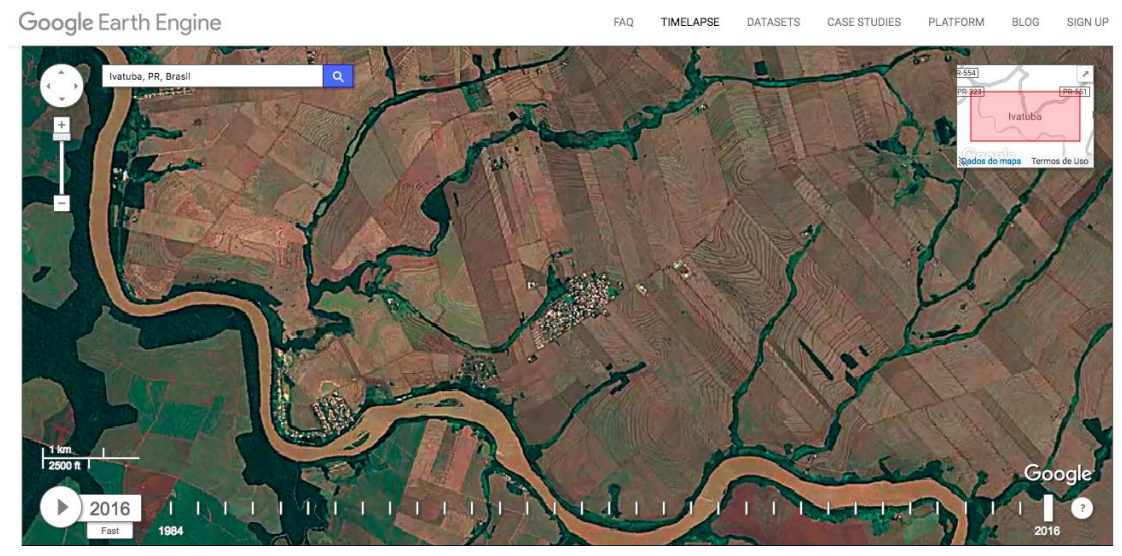

Fonte: Arquivos do Google Earth Engine

Para o acompanhamento em EaD das atividades, foi disponibilizado o Moodle do laboratório de informática da Escola. Na medida que o relacionamento ocorria, via 
Ambiente Virtual de Aprendizagem (AVA), os estudantes perceberam que somente 0 grupo instituído não conseguiria resolver a situação apresentada, pois essas exigiam novas demandas que foram surgindo, pois novos dados e elementos foram incorporados à resolução do problema. Na medida que esses dados foram sendo acomodados, novos integrantes seriam necessários.

Assim, novos contatos foram sendo estabelecidos via softwares de redes sociais, principalmente o whatsapp. e membros de alguns grupos saíram para se juntaram à equipe que agora convidava, oferecendo suas expertises, para a soma de conhecimentos necessários a tarefa (GOMES, 2014). Para jovens da zona rural, esse entendimento do que os cerca, levou-os a outros questionamentos, especialmente ligados a pulverização de grandes quantidades de veneno nas plantações e possíveis causas gênicas.

Assim se construiu o conceito de comunidade de prática (CoP) na educação (SIEDLOK, HIBBERT, SILLINCE, 2015), onde os indivíduos se reúnem para compartilhar suas experiências pessoais em busca de uma solução prática para o problema (RAMOS, MANRIQUE 2015). Em cada grupo, pudemos explorar outras frentes de análise e subsídios para pesquisas, como a função Timelapse, onde todas as imagens ficam armazenadas ao longo do tempo e podem então ser fornecidas em modo visualização.

O GEE armazena imagens dos últimos 30 anos, permitindo ao aluno acompanhar e comparar, por exemplo: o desmatamento, a dispersão de espécies nativas, a introdução de espécies não nativas e sua interação, bem como, a expansão urbana, a área cultivável, o desvio de rios e córregos, as mudanças climáticas, entre outras.

\section{DISCUSSÃO DOS RESULTADOS}

Percebemos um distanciamento entre o que se aprende em sala de aula, com aquilo que vislumbra-se no cotidiano. Ao coletar informações com os alunos, muitos deles nos confessaram que tudo o que aprendem, deve ser aprendido pois "cai no vestibular ou no ENEM". Essa mesma situação nos foi retratada pelos professores, que estão carentes de sugestões de como conduzir determinados temas. Assim, foi possível coletar as frases dos alunos que mostraram sua absorção dos objetivos propostos, pois esses,

Não sabia que o google Earth tinha essa função. E olha que fuço isso o dia inteiro. Foi muito legal, poder acompanhar ao longo do tempo, a construção da cidade e o plantio de soja. Meu pai trabalha com isso, sabe! (GFS, 16 anos).

Para tanto, por mais que a informação esteja em todos os lugares, escolher e gerenciar essas plataformas tem sido muito complexo. Nossa experiência age no sentido de informar e prover um recurso que será utilizado como material didático, como ferramenta, um meio de ensino que complementem e ampliem o trabalho feito em sala de aula. 
A experiência foi muito boa. Meu grupo descobriu que o olho d'água da fazenda $X$, sumiu. Nós brincávamos lá sabe. Então, precisamos conservar a vegetação que nos rodeia e preservar o que ainda sobrou. Sei que a plantação é que dá dinheiro, mas precisamos achar uma solução melhor! (JL, 17 anos).

Salientamos que o planejamento deve propiciar um start inicial, um gerador do debate, como o uso de jornais e revistas da cidade a ser analisada, por exemplo, de porque meu bairro está "superlotado" de pessoas? Por que a enchente arruinou somente essa área da cidade? Entre outras questões, que poderão ser visualizadas e analisadas com o uso desse software. Como reforça Vieira (2005, p.3), para que estas tecnologias "promovam as mudanças esperadas no processo educativo, devem ser usadas não como máquinas para ensinar ou aprender, mas como ferramenta pedagógica para criar um ambiente interativo".

\footnotetext{
Acompanhei todo o processo e junto com o grupo discuti as formas pedagógicas do uso desse software. Realmente o impacto nos alunos foi além do que esperava. Eu aprendi muito. Já estou organizando o uso do software em minhas aulas de Geografia (professor MM, 45 anos, participante fora da área).
}

Quando professor e aluno ampliam o conteúdo programático, de forma a permitir uma investigação mais dinâmica de sua condição social, há uma verdadeira colaboração intelectual. Se essa contar com a mediação de tecnologia, linguagem a que os jovens possuem amplo acesso, poderão dividir experiências das mais diversas. Quando esse ambiente é criado, os problemas são agora resolvidos como parceria, transformando os agentes tradicionais em gestores do conhecimento, um processo de colaboração que não tem fim.

\section{CONSIDERAÇÕES FINAIS}

O aprender com significado só existirá num ambiente onde professor e aluno estão pesquisando, debatendo e criticando esse saber. Novas tecnologias são bem vindas não como algo estático e pronto, mas como algo que possa ser usado como ferramenta, que possa dar significado as questões sociais. A sala de aula encontra-se carente de processos auxiliares, ferramentas que possam ampliar o processo ensino e aprendizagem. Os alunos possuem grande apreço pelas tecnologias, então unir TDIC e sala de aula, muito podem contribuir para o processo educativo.

Dentro de um planejamento eficiente, as TDIC irão contribuir para uma aprendizagem efetiva, que deixa de ser enciclopédica e passa a permitir, de forma globalizada, uma ação cidadã. Para isso, capacitar os professores para o uso das TDIC é de fundamental importância.

O software educativo "é uma dessas ferramentas privilegiadas que podem integrar favoravelmente o projeto pedagógico da escola, ampliando a efetividade do processo 
ensino aprendizagem" (OLIVEIRA, 2001, p. 87). Esse ambiente de aprendizagem se desvincula do conteúdo programático, pois o amplia a construção de criativas formas de abordagem e resolução de problemas, pois age como

facilitador de uma aprendizagem com maior qualidade e permitindo um avanço pedagógico da escola. Esses ambientes irão favorecer a comunicação, a cooperação e colaboração entre professores e alunos, tornando esta nova maneira mais estimulante e divertida (MERCADO, 2002, p. 134).

A medida que explora o ambiente virtual, as funções do software, o aluno é capaz de interagir com as novas informações e gerar novos conhecimentos capazes de influenciar na mudança de postura frente as necessidades do ambiente. Essa construção própria, carregada de significado, intencionalidade, faz com que os alunos aprendam a valorizar o significado de outrem, da mesma forma que o desejam para si; e assim (re)construir conhecimento, a partir da análise do cotidiano, como elemento fundamental a um país que precisa de inovações nas mais diversas áreas.

\section{REFERÊNCIAS}

BESKOW, C. A. Inclusão digital na escola pública: relacionando comunicação, tecnologia e educação. 2015. Disponível em: . Acessado em 15/10/2015.

BIZZOTO, N.M. Metodologia e prática de ensino de ciencias: A aproximação do estudante de magisterio das aulas de ciencias no $1^{\circ}$ grau. Faculdade de Educação da USP, 2000.

CANÃ, B.B. ROSA, K. K. COSTELLA, R. Z.. Análise da transformação da floresta amazônica a partir do uso de geotecnologias - google earth engine - nas aulas de geografia do ensino fundamental. Boletim Gaúcho de Geografia, Associação dos Geógrafos Brasileiros. v. 42, n.2: 553-567, maio, 2015.

GIMENES, Camila Itikawa. Um estudo sobre a epistemologia da formação de professores de ciências: indícios da constituição de identidades. Curitiba: 2011. Dissertação (Mestrado) em educação - Setor de Educação, Universidade Federal do Paraná.

GOMES, H. F. A dimensão dialógica, estética, formativa e ética da mediação da informação. In: Revista Informação e Informação, Londrina, v. 19, n. 2, maio/ago. 2014. Disponível em: . Acesso em: 22 maio 2017.

GOOGLE EARTH ENGINE. Tutorial Introduction. Publicado em 15/05/2016. Disponível https://www.youtube.com/watch?v=uHtehTSw7vg Acessado em15/05/2017. IBOPE. Instituto Brasileiro de Opinião Pública e Estatística. Pesquisa 2009. Disponível em: .Acessado em 15 jan. 2013.

LIBÂNEO, J. C. Organização e gestão escolar: teoria e prática. Goiânia: Alternativa. 2001. 
MERCADO, L. P. L. (Org.). Novas tecnologias na educação: Reflexões sobre a prática. Maceió: EDUFAL, 2002.

OLIVEIRA, C. C. Ambientes informatizados de aprendizagem: Produção e avaliação de software educativo. Campinas, SP: Papirus, 2001.

OLIVEIRA, E. A. et al. Estilos parentais autoritário e democrático-recíproco intergeracionais, conflito conjugal e comportamento de externalização e internalização. Psicologia: Reflexão e Crítica, 15(1), 1-11. 2002.

RAMOS, W. R., MANRIQUE, A. L. Comunidade de Prática de Professores que Ensinam Matemática como Espaço de Negociações de Significados sobre a Resolução de Problemas. In: Bolema - Boletim de Educação Matemática, v. 29, n. 53, p. 979-997. Rio Claro (SP). 2015.

RODRIGUES, L. P.; MOURA, L. S. \& TESTA, E. Tradicional e o Moderno Quanto a Didática no Ensino Superior. $2016 . \quad$ Disponível em: http://www.itpac.br/arquivos/Revista/43/5.pdf . Acessado em 02/02/2017.

SIEDLOK, F., HIBBERT, P. SILLINCE, J. From practice to collaborative community ininterdisciplinary research contexts. In: Research Policy, v.44, n.1, p.96-107, February, 2015

SIEDLOK, F., HIBBERT, P. SILLINCE, J. From practice to collaborative community ininterdisciplinary research contexts. In: Research Policy, v.44, n.1, p.96-107, February, 2015

TAKAHASHI, T. (Org.). O livro verde: a sociedade da informação no Brasil. Brasília: Ministério da Ciência e Tecnologia. 2000. Disponível em: . Acessado em 20/07/2016. TONINI, I.M. Movimentando-se pela Web 2.0 para ensinar geografia. In: Movimentos no ensino de Geografia. Org.: Antonio C. Castrogiovanni, et all. Porto Alegre: Compasso Lugar-Cultura, 2013.

VALENTE, J. A. (Org.). O Uso Inteligente do Computador na Educação. In: Pátio: Revista Pedagógica. Porto Alegre: Artes Médicas Sul. ano 1, n.ำ 1, 1997.

VIEIRA, F. M. S. A Utilização das Novas Tecnologias na Educação numaPerspectiva Construtivista. Disponível em: . Acesso em: 16 set. 2005.

TODOSPELAEDUCAÇÃO (TPE). 2016. Disponível em: < http://www.todospelaeducacao .org.br/educacao-na-midia/indice/27028/so-2-dos-professores-usam-tecnologia/> , acessado em 09/03/2017. 